\title{
Experience economy in the system of culture and education
}

\author{
Lyudmila Pushkareva ${ }^{1}$ and Mikhail Pushkarev ${ }^{2, *}$ \\ ${ }^{1}$ North-West Institute of Management, branch of RANEPA, 199178, Sredny prospect VO, 57/43, St. \\ Petersburg, Russia \\ ${ }^{2}$ Saint-Petersburg State Institute of Technology, 190013, 26 Moskovsky prospect, St. Petersburg, \\ Russia
}

\begin{abstract}
The economy of impressions in which the new level of interaction is formed between brands and target audiences gaining particular importance in new market reality. The company in a service sector, including higher education institutions, becomes the provider of "impressions" under these conditions. Impression economy includes art collaboration methods and tools in which different brands take an active part. Currently, cooperation between educational institutions and the art and cultural industries is becoming one of the effective mechanisms for promoting educational brands, increasing consumer loyalty, creating competitive market superiority. The article considers cooperation in the context of the Virtual Museum project between brands such as the Russian State Hydrometeorological University (RSHU) and the Russian Museum.
\end{abstract}

\section{Introduction}

The modern world is undergoing a new stage of evolutionary development. Such changes entail changes in many spheres of human activity, including education, culture, economy, creating new conceptions and approaches, such as behavioural economy, confidential marketing, marketing of relationship, economy of impressions etc.

The term "economy of impressions" gets a special sense and value in new market reality that has gone beyond three classical economic categories: "raw materials - goods services". The economy of impressions describes the emergence of the new, fourth economic category - "impression". Impressions is a special economic offer. They cardinally differ from services and goods.

With the development of the economy of impressions a new level of interaction of brands with target audiences is formed. In new reality the perception of consumer value changes. Impressions become an independent product and object of purchase and sale, and in the chain "raw materials - goods - services - impression" the share of the added value is more and more shifted to the "impression" [1].

In these conditions any company in the service sector, including higher education institutions, becomes the supplier of "impressions". It demands targeted effort and shapes significant conditions for the company development. Price and quality are not indisputable

* Corresponding author: malexpush@,bk.ru 
conditions of the brand competitiveness any more. High quality standards are perceived by consumers as natural process and a prerequisite for the emergence of a brand in the market. The market demands from the brand uniqueness, and it's impressions and experience that provide this uniqueness.

It is necessary to show the dual character of the brand. On the one hand the brand acts as a communication form, it symbolizes both material and intangible aspect of the company, representing its main values, aspirations and purposes.

On the other hand, the brand offers a much wider range of the received service or production application opportunities, thanks to which it provides associative capacity. It allows establishing close relationship with consumers at the emotional level [2].

Today it is getting increasingly difficult for the companies to build and handle consumer loyalty to the brand, as now consumer loyalty is connected with the emotional involvement of the consumers rather than with the satisfaction of the buyers. It plays the crucial role in the modern process of purchasing goods of a particular brand [3].

Change of consumer orientations has led to brands satisfying consumers' own ideas of their status, role and significance in society.

Establishment of the long-term relations with consumers, formation of stable relations in the market are promoted by empirical marketing. Possessing its own specific features, empirical marketing considerably differs from the traditional. Here the accent is put on emotional experience of the consumer, recognition of the both rational and emotional motives which allow various marketing strategy and methods. As a result it also changes approach to branding [4].

In conditions of traditional marketing the brand is the goods identifier possessing branded properties (a name, a logo, a slogan) and influencing awareness and image in the market environment. In empirical marketing the brand is regarded as the concentrated expression of impression which directly affects the consumer at the touch-sensitive and emotional levels. In this case "joint branding" or "co-branding" are quite appropriately used for productive development in modern marketing conditions. Similar terminology is used in relation to a particular form of sharing brands of two or more companies after having united their marketing efforts [5].

Taking part in creative cooperation, brands of the companies seek:

- to interact with the public, showing a high level of social responsibility;

- $\quad$ to expand consumer base at the expense of the target audience of the partner;

- to emphasize their own value and a creative component which distinguishes the company from its competitors;

- to involve internal and external public, infringing on their interests at a deeper level;

- $\quad$ to develop innovative market strategies and technologies.

Researchers allocate three main components in cooperation of the company brands with culture and art.

1. Socializing component of brand cooperation means inclusion of the consumer in cultural space by means of marketing, advertizing and distribution.

2. Economic component defines the mode of production and the way of its organization.

3. Creative component is responsible for a consumer involvement into hybrid form of cooperation [6].

Thanks to the prompt development of culture industry and support from the government bodies new tendencies on the establishment of creative partnerships have been built. They differ in structure and active approach focused on a high-quality result:

- control of the ethical component of partner projects and objectives of the companies; 
- formation of interactive communications around art projects with the help of social networks and the Internet;

- active involvement of art and culture experts and consultants;

- introduction of multimedia technologies;

- $\quad$ emergence of "hybrid" spaces [7].

\section{Materials and methods}

The main characteristics of the economy of impressions are an important role of new technologies and modern discoveries in various areas of human activity. The economy of impressions also includes methods and tools of art collaborations in which active part is taken by various brands. Production companies seek to be integrated into the sphere of art, despite considerable distinctions between industries. Similar cooperation is caused by mutual advantage which becomes available due to the partnership on mutually advantageous conditions.

Degree of readiness of the phenomenon of the economy of impressions and empirical marketing relies on works of domestic researchers of the school of marketing of UNECON (Saint-Petersburg State University of Economics): prof. G. L. Bagiyev and O. U. Yuldasheva, as well as Shirshova O. I., Betekhtina D. A., Beaver E. A., Borovinska, D.N., T. M. Krivosheyeva, N. V. Havanov, Schmitt B., D. Rogers, K. Vrotsos [3; 8-10]. Joseph Pine and James Gilmore [11], developed the theory of economy of impressions and argumentatively described the sequence of transition from raw economy to commodity economy, then to service economy, and further - to the economy of impressions. Specific features of marketing of culture industries and education services were developed by $\mathrm{O}$. V. Vaneeva, A. A. Vasnetsky, S.E. Drobysheva, A. V. Krivova, O. V. Lazareva; [6; 12-14], study of the modern phenomenon of co-authorship of value and buyer was undertaken by Kapustina L. M. and Elayeva A. [7; 15].

Russian state hydrometeorological university (FGBOU VO "RSHU") and the Russian Museum (St. Petersburg) participate in the study of the efficiency of education institution brand promotion through collaboration of brands with the sphere of art and culture. Statements of the federal educational target programs, non-financial reports of FGBOU VO "RSHU" and the State Russian Museum, the analytical researches of the higher education service sector taken from the official sites and social networks served as analytical materials.

\section{Discussion}

Higher education institutions have well-manifested specific features of their service promotion based on the final product: firstly - education service, secondly - the expert trained for labor market. Notably education service has its special features distinguishing it from other services. Before speaking about the process of brand of a higher education institution formation and development it is necessary to agree upon the definition of "education service".

The Law of the Russian Federation "About education" does not contain the official definition of education services. The general concept of service is enshrined in the Tax code of the Russian Federation - services are activities the results of which have no material expression, are realized and consumed in the course of implementation of this activity. F. Kotler defines service as "any action or benefit which one party can offer to the other and which is generally intangible and does not lead to the acquisition of something" [16]. 
For the definition of the concept "education service" many researchers quote L. Chentsov who writes in the article "About Business of Education Services": "Education services are created in the course of the scientific and pedagogical work, which, in its turn, is a kind of scientific work. The result of scientific work can be called an educational product" [17]. D. Shevchenko in the definition of education service proceeds from the purposes of the Federal state standard of a higher education (FGOS VO), which defines education service as a "process of receiving a certain amount of knowledge and practical ways of its application able to satisfy needs of the personality for the professional status and growth" [18].

One of the disputable topics in the activity of education institutions is considered the question what the final product of the educational process is. In fact, higher education institutions conduct their activity in educational and labor markets simultaneously: providing education services to the society in the former, and well-trained staff to various industries of national economy in the latter.

However most researchers stick to the opinion that a product of any education institution is "a complex of education services aimed at changing the level of education or vocational training of the consumer carried out by appropriate resources of education institution" [19].

In their choice of a higher education institution applicants as a rule, choose educational programs which ensure their gain of knowledge as a criterion of the educational program quality.

However due to the fact that any higher education institution operates simultaneously in two markets, it is necessary to take into consideration the level of its graduates. After all a higher education institution is one of the crucial factors in shaping the identity of the graduate through building in them a lot of values which they will follow in their further activities. For this reason both internal environment and external attributes, as well as the image of its graduates play an important role in the formation of a higher education institution brand.

Creation of an educational brand by a higher education institution, certainly, gives it a number of advantages which go as follows: it forms consumer loyalty; provides entry competition that allows to accept the most well-prepared applicants; renders services with a full cost recovery provides considerable inflow of extrabudgetary funds both due to a relatively high payment, and to the increase of the number of people interested to be trained on the fee basis;

allows to count on target enrollment and sending students to a fee-based training at the expense of the organizations and companies-prospective employers of the graduates; creates more ample opportunities for participation in research, design and social projects which are carried out at the expense of funds, means of the companies and other nonbudgetary sources; facilitates establishment and provides stability of international relations.

The educational brand includes the following components:

- uniqueness and recognition of the system of branded designations, such as the name of a higher education institution, the graphic representation (logo) and others;

- product or education service with all the inherent characteristics (quality of education, faculty, training conditions and so forth);

- image of the higher education institution as a set of characteristics, expectations, associations perceived and attributed to a higher education institution by the consumer and the public;

- the mission and the values of a higher education institution, which are expressed as promises of advantages given by the owner of a brand to the consumers of educational services. 
All this makes up the brand identity. The essence of the brand can be expressed by the mission of a higher education institution [20]. However practice shows that many Russian higher education institutions approach to the mission elaboration formally, without realizing its main objective - deep involvement into the life of the society, even though it's the mission of a higher education institution that becomes fundamental for the creation of its branded policy.

Integrated marketing communications help to develop positioning of a brand in the consciousness of the target audience and the society. However due to the economic feasibility it's not direct advertizing, but the BTL tools such as PR methods, special events arrangement, implementation of loyalty programs, participation in public programs and partner projects that come into the forefront in educational branding [21].

In Russia one of the forms of brand cooperation is integration of education institutions and museums.

Development of new forms and ways of communication with the target audience and the society in general generates the need for new self-identification and positioning of the both in the real social environment, and in virtual space. Museums go beyond their habitual exposition activity and provide audiences with more active, and also interactive forms of reproduction and perception of the information.

Creation of virtual museums is caused by the prompt development of the economy of impressions, which has led to the fact that the modern consumer is not satisfied with receiving only information product: society demands innovative methods of involvement into culture space. Personalisation of the audience in virtual sphere represents a wide range of interests and allows both the museum, and the education institution to understand preferences of the audience and offer a number of services and projects for an effective and long-term interaction. Museums initiating creative partnerships are aimed at cooperation with education institutions, which is favorable to both parties. This relationship is focused on the visitor's individual training and directed on promoting knowledge in museum space. Such cooperation provides higher education institutions with a number of competitive advantages:

- creation of the corporate image and strengthening its reputation;

- $\quad$ high competitiveness in the market of education services;

- appeal among the target groups of the public;

- friendly relations with foreign higher education institutions and exchange of experience;

- investment appeal.

\section{Results}

For the disclosure of the opportunities of the virtual museum in the system of university promotion we will consider this model on the example of the federal state budgetary education institution of a higher education "Russian State Hydrometeorological University", further - RSHU. The higher education institution possesses the status of the regional training center of the World Meteorological Organization and the first-ever university of a hydrometeorological profile. According to the official statistics of the Ministry of Education and Science of the Russian Federation - RSHU is among the best and highly-demanded Russian higher education institutions (the rating of higher education institutions of 2018: The 125th place in the Russian Federation, the 15th place in St. Petersburg).

RSHU cooperates with scientific and education institutions in more than 31 countries of the world: The University of Plymouth in Great Britain, Leipzig university in Germany, Danish meteorological institute, the International language school Education First etc. 
The university develops fundamental and applied researches in the field of meteorology, hydrology, oceanology, climatology, information technology, environmental protection and rational environmental management. In 2011 RSHU became the owner of the "Megagrant" - a grant of the Ministry of Education and Science of the Russian Federation focused on attraction world famous scientists to the higher education institutions of the country. Within the framework of the Sciences about Earth program in RSHU the famous French scientist Bertrán Shapron from the research institute of studying and operation of resources of the sea IFREMER is engaged in scientific researches.

The higher education institution takes an active part in the international scientific and practical conferences "INFOGEO" and "EKOPR", and also in the international CALMet conference where it acts as the representative of Russia among 25 member countries.

The university acts as the leading partner of "the Scandinavian-Russian university network for the successful development of cooperation in higher education in the field of environmental sciences". Since 2002 RSHU is also included into the program of university development of network cooperation of UNESCO and is the member of the American program of the Arctic researches ARCUS. Besides, in 2010 RSHU housed the international conference "The Baltic Sea Science Congress".

Besides participation in the activities of the international level, the higher education institution is the honorary member of the global funds for financing research projects such as the Framework program of the European Commission, the Nordic Council of Ministers, German research society, European scientific fund, American council for the international researches and scientific exchanges (AYREKS). The university is also included into the list of scholarsholders of the Smithsonian astrophysical observatory.

Today the main directions of the development and promotion of the RSHU brand is interaction with mass media, organizing and holding special events; presentations and personal contacts with the representatives of the target audiences, positioning of the higher education institution and its services in the global information network as well as the support of the image of the higher education institution in the sphere of promotional and informational activity and by means of partner cooperation, including cooperation with the Russian Museum.

The State Russian Museum is the world's largest collection of the Russian art founded in the XIX century by the emperor Alexander III; it has a rich history and the world value. The collection of the Russian Museum counts about 400000 exhibits and covers all the directions of development of the Russian art throughout the historical period of more than 1000 years. The collection is placed in Mikhaylovsky, Stroganovsky, Marble palaces and Mikhaylovsky castle. Mikhailovsky Garden, the Summer gardens with a lodge of the emperor Peter I are also a part of the museum complex.

Today the Russian Museum is righteously considered the largest authoritative research, restoration, storage, and methodical center supervising the work of all the art museums of the country. In 1997 the Friends of the Russian Museum, which is a charity foundation of 400 people, 85 companies and organizations was created. Philanthropists participate in the life of the museum, giving financial, technical and organizational aid in implementation of the scientific, restoration, exhibition and exposition and educational programs and projects of the museum.

The modern museum is a complicated, multilevel system solving a number of socially significant problems among which the increasingly noticeable position is taken by an educational program of leisure integrating informative, entertaining and art creative functions. With the emergence and development of the Internet the public developed the demand for direct interaction with an exposition assuming indispensable feedback. Such opportunity is provided by modern interactive technologies lifting the museum exposition to a new level. They allow visitors to interact actively with the exhibits and receive more 
detailed information that contributes to its better perception thanks to the creation of the effect of participation.

For this reason and with purpose of assistance in cultural and educational activity development in 2011 the "Systema" charity foundation became non-commercial partner of the State Russian Museum entering the list of the honorary corporate members of the Friends of the Russian Museum organization. Thanks to this collaboration the museum took a lead and started coordination of the new cultural and information environment formation among youth and students and the Virtual museum became an ambitious project in the sphere of innovative technologies.

The electronic portal has been in action since 2003 as the international center aimed at familiarizing with the public with the values of the Russian art and culture on the basis of free access to electronic and digital materials. Using the possibilities of the modern means of communication and the latest computer technologies, the virtual platform is urged to create common cultural information space in the territory of Russia and the adjacent states. Expansion of the scope of scientific, enlightment and educational programs is to be reached through:

- $\quad$ cooperation with Federal state budgetary institution of culture "The State Russian Museum" in the implementation of the project "The Russian Museum: virtual branch";

- contribution to the increase of the cultural level of the population by the development of the programs and projects directed on creation of multimedia content in the sphere of art;

- digitization of the works of art belonging to the collections, in particular, of the Russian Museum;

- $\quad$ ensuring the presence of "The virtual Russian Museum" and other projects and programs in the social information environment (the sites on the Internet, social networks);

- cooperation with the relevant organizations and experts in education and science, culture and arts for the implementation of the programs and projects designated in the Charter "The Virtual Russian Museum".

Now interactive activity of the museum is supervised by the special department of the project "The Russian Museum: virtual branch" development, which is the interregional and international project promoting the idea of the Russian art collection availability to the widest possible audience, largest in Russia, outside St. Petersburg. Its purpose is familiarizing the wide audience with the values of the Russian culture and Russian historical past by means of free access to electronic, digital and printed materials, as well as formation of the common cultural information space for the participants of the project.

The museum works in the edutainment format (self-training) with the purpose of drawing the humanities students' attention, and making it popular with the general population.

Interactive and classical methods of training are urged to promote formation of the students' positive motivation and steady interest in research work. Resources of the center (the library, the media library, the Internet resources of the IOTs network and the State Russian Museum) and a base of scientific and methodical materials of various kinds of humanities have unlimited access. Computer technologies open an extensive field for work with audiovisual maintenance of alternative authoritative sources of information. Efficiency and practical importance of the project is explained by the fact that large volumes of information are better acquired by means of visualization of the objects of studying which the museum is focused on and works of art belonging to it.

In February, 2018 the Russian Museum opened the 205th virtual branch in RSHU. The latest branch became the 10th center opened on the basis of the higher education institution in St. Petersburg. 
The project carries the name "Media Library in the Library" and corresponds to the newest strategy of the Russian Museum. In return the resource in many respects responds to the objective request of the university for the humanities component in the students' training, and also corresponds to the specific features of the higher education institution. The activity of the information and education center "Russian Museum: the virtual branch" is carried out by qualified specialists in the field of art and education, the latest technologies and museum pedagogics. The informative project includes multimedia movie theater and an information and education class. The media library unites the materials devoted to constant expositions of the Russian Museum. Thanks to the saturation of the information materials the center conducts seminars, practical and laboratory researches, and also independent work of students and teachers.

For educational process within the framework of educational and extracurricular activities of RSHU the virtual branch of the museum allows:

- $\quad$ to staturize and expand knowledge of various specializations in the sphere of the humanities, graphic and applied arts;

- $\quad$ to develop the skills of the professional in the search and informative reading;

- $\quad$ to stimulate the professional focused on cross-cultural research activity.

Having designated the main activities of virtual branch of the Russian Museum, it is possible to come to the conclusion that cooperation with the virtual museum is the instrument of advancement allowing the University to interact in the long term with all the target groups of the public. To carry out its activity the Russian Museum needs partners cooperation with which is within the framework of its interests as well as the interests of the University.

During the interaction of the RSHU brands and the Museum within the virtual branch it is difficult to estimate the efficiency of cooperation and to draw objective conclusions as the process of interaction is at a stage of development and will serve as a scientific research further on. However it should be noted that the project "The Russian Museum: the virtual branch" has not stopped since the moment of foundation in 2010, showing continuous expansion of the partner base and increase in the number of the developed materials. It is becoming the major factor which allows to estimate work on a large scale, without resorting to consideration of particular cases.

Virtual expositions often promote growth of attendance of the real museums, and high technologies allow recruiting the youngsters and students audiences. Studying this question We analysed special literature and internal documents of the company (the plan of communication campaign and the conducted market researches).

The official statistics provided in open access on the official site of the State Russian Museum shows that today the annual total number of the visitors of the virtual branches of the Russian Museum makes up more than 500 thousand people. It confirms the tendency of the last four years during which the number of visitors only of one lectures in the branches all over the country has increased more than by 11 times. According to "the Sistema" charity foundation, which acted once aas a co-initiator of the project creation, "over the lifetime of the project it has been visited by more than 3 million people, and the database of an interactive media library has increased by 5 times".

For a higher education institution a special appeal of the project consists in the continuous replenishment of the content of multimedia programs, and also carrying out information and education and entertaining lectures with the assistance of the museum staff, which cannot but attract applicants for different programs of the University. It is important that the virtual branch is developed for cooperation on a constant basis. This factor allows RSHU to build a strong link with the target audience during the communicative activity and to increase interest in the higher education institution on the education services market. 
Permissibly also to note that the project considered above served as the basis for the final qualification work focused on the development of the mechanisms of the declared brands promotion within the framework of their collaboration, which shows one more direction of the efficient brand cooperation - scientific research.

\section{Conclusion}

Thus, today higher education institutions are innovative platforms which actively interact with public structures at various levels. Such transformation leads to the expansion of the target groups of the public, which, in its turn, speaks about the need for a change in positioning higher education institutions and formation of a new system of promotion with introduction of innovative technologies.

\section{References}

1. J. Dwyer, N. Hopwood, The business communication handbook (Cengage AU, 2019).

2. N. Klein, No Logo. People against brands (Kind book, 2012).

3. E. A. Bobrova, O. U. Yuldashev, I. Y. Okolnishnikov, Bulletin of the Udmurt University 2-1, 74-85 (2011).

4. B. Schmitt, D. Rogers, K. Vrotsos, Business in style of show. Marketing in culture of impressions (Williams, 2005).

5. F. V. Vodovozov, Transport Business of Russia 4 (2010).

6. O. V. Lazareva, Messenger SPBGUKI 3(32) (2017).

7. J. E. Schroeder, Marketing Theory 9(1), 123-126 (2009).

8. D. A. Betekhtina, Problem of modern economy 4 (2010).

9. D. N. Borovinskaya, Messenger of Tomsk state university 388, 47-53 (2014).

10. K. N. Lemon, P. C. Verhoef, Journal of marketing 80(6), 69-96 (2016).

11. B. J. Pine, J. X. Gilmore, Economy of impressions. Work is a theater, and each business - a scene. (Williams, 2005).

12. R. Bridgstock, S. Cunningham, International Journal of Cultural Policy 22(1), 10-26 (2016).

13. A. V. Krivova, The Brand management 3(52) (2010).

14. M. Peltoniemi, International journal of management reviews 17(1), 41-68 (2015).

15. B. Shen, T. M. Choi, P. S. Chow, Journal of Business Research 81, 173-180 (2017).

16. F. Kotler, G. Armstrong, J. Saunders, V. Wong, Fundamentals of marketing. (Williams publishing house, 1999).

17 . J. Daniel, E. V. Cano, M. G. Cervera, International Journal of Educational Technology in Higher Education, 12(1), 64-73 (2015).

18. Y. V. Nadtochy, E. N. Klochko, M. V. Danilina, et al., International Review of Management and Marketing 6(1S), 33-39 (2016).

19. O. V. Saginova, Marketing in Russia and abroad 1 (1999).

20. A.V. Kofanov, Z. I. Ivanova, K. S. Elenev, Marketing and market researches 1(91) (2011).

21. L.V. Pushkareva, O.A. Galochkina, O.L. Bezgacheva, Espacios 4(40) (2019). 